\title{
O desempenho das universidades brasileiras no U-Multirank e Ranking Universitário Folha
}

\author{
The performance of Brazilian universities on U-Multirank and Folha University Ranking
}

\author{
Janaina Lais Pacheco Lara Morandin \\ Graduanda em Biblioteconomia \\ Universidade Federal do Rio Grande do Sul \\ janainalaramorandin@gmail.com \\ Natália Rodrigues da Silva \\ Graduanda em Biblioteconomia \\ Universidade Federal do Rio Grande do Sul \\ natalia.rodrigues@ufrgs.br \\ Samile Andrea de Souza Vanz \\ Doutora em Comunicação e Informação \\ Universidade Federal do Rio Grande do Sul \\ samilevanz@terra.com.br
}

\begin{abstract}
Resumo
A hostilidade inicial perante os rankings universitários foi paulatinamente perdendo força em função da possibilidade de melhorias institucionais a partir das comparações por métodos, em geral, quantitativos. O papel nacional ou regional das instituições, na formação em graduação e na prestação de serviços à comunidade são, de fato, temas relevantes e geralmente subvalorizados pelos rankings internacionais, porém ganham destaque em alguns rankings nacionais. Neste contexto, o presente artigo objetiva compreender e discutir as metodologias utilizadas por dois rankings distintos, o ranking internacional U-Multirank e o nacional Ranking Universitário Folha, buscando expandir a perspectiva de compreensão acerca do tema e o aprofundamento da discussão acerca destes rankings aqui no Brasil. $O$ estudo fundamenta-se em uma revisão de literatura sobre rankings universitários, especialmente o U-Multirank e o Ranking Universitário Folha. Utiliza pesquisa bibliográfica e documental, com coleta de dados nos sites dos respectivos rankings. Observou-se que as instituições de ensino brasileiras são grandes e generalistas, o que dificulta a visibilidade internacional. Porém, o resultado do ranking nacional apresentado mostra-se similar ao internacional, na comparação entre as instituições. A análise da metodologia utilizada pelos rankings indica os pontos negativos e positivos que influenciam na avaliação das universidades. Conclui-se acerca da relevância do debate sobre o tema, considerando-se que os rankings universitários permitem uma discussão sobre as universidades que sem dúvida, contribui para o aperfeiçoamento das instituições e, em última análise, do sistema de educação do país.
\end{abstract}

\section{Palavras-chave}

Rankings universitários. U-Multirank. RUF. Universidades brasileiras.

\section{Abstract}

An initial hostility displayed over the university rankings was gradually lost due to the possibility of institutional improvements based on comparisons by methods, in general, quantitative. The national or regional role of institutions, undergraduate training and community services provision are in fact, 
relevant themes which are generally undervalued by international rankings, however they are highlighted in the national ones. In this context, the paper's goal is understand and discusses how the methodologies used by two different rankings, the international U-Multirank and the national Ranking Universitário Folha, seeking the perspective of understanding the theme and deepening the discussion here in Brazil. The study is based on a university rankings literature review, regarding especially the U-Multirank and the Ranking Universitário Folha. It uses bibliographic and documentary research, with data collection on the ranking's websites. The results showed that Brazilian educational institutions are large and generalist, which hinder international visibility. However, the results presented by the national ranking is similar to the international one, in the comparison between institutions. An analysis of the methodology used by the rankings indicates the negative and positive points that influence universities evaluation. The conclusion goes towards the relevance of the topic debate, considering that the university rankings provide a discussion about the universities that contribute to the improvement of the institutions and, ultimately, of the country's education system.

\section{Keywords}

University Rankings. U-Multirank. RUF. Brazilian Universities.

\section{INTRODUÇÃO}

Os rankings universitários se configuram na análise das Instituições de Ensino Superior (IES) a partir de indicadores que pretendem ofertar uma ideia geral das mesmas. Desta forma, os rankings buscam conceituar aspectos que abranjam as diversas atividades desenvolvidas pelas universidades, utilizando um conjunto de critérios pré-definidos que, somados, culminam em uma pontuação final para cada universidade (RIGHETTI, 2016). Geralmente, os indicadores utilizados referem-se à produção científica dos docentes, à relevância da pesquisa na instituição, à qualidade da inserção dos egressos no mercado de trabalho e, no caso dos principais rankings, chamados league tables, é levada em consideração, também, a reputação da universidade frente à opinião de acadêmicos e empregadores (VANZ, 2018). Dessa forma, cada ranking adota sua própria metodologia, onde o conceito atribuído a cada indicador pode ser coletado através de bancos de dados nacionais e internacionais, pesquisas de opinião e por meio de informações fornecidas pela própria instituição.

Alguns rankings internacionais, como o Academic Ranking of World Universities (ARWU), Leiden Ranking, QS University Rankings, The Times Higher Education (THE) e o nacional Ranking Universitário Folha (RUF) são unidimensionais, ou seja, dispõem de uma tabela de classificação com pontuações nos diferentes indicadores. Uma tabela de classificação é uma lista ordinal que vai do melhor ao pior, atribuindo às entidades posições únicas e aparentemente equidistantes uma da outra (WESTERHEIJDEN, 2014). Diferentemente dos demais, os rankings multidimensionais como o internacional U-Multirank (UMR), apresentam uma série de indicadores que podem ser organizados de acordo com as preferências de quem realiza a consulta, permitindo comparações entre diversas IES utilizando os filtros presentes em suas plataformas.

Estima-se que existam cerca de dez rankings universitários globais com periodicidade definida e critérios previamente estabelecidos que se debruçam sobre universidades de todo o mundo, além de cerca de sessenta rankings nacionais que avaliam universidades de um mesmo país (RIGHETTI, 2018). No Brasil, a discussão sobre rankings surgiu em meados de 1990, com a proposta de "[...] aferir qualidade a partir das três principais atividades de uma universidade: pesquisa, ensino [de] graduação e pós-graduação e extensão universitária." (CALDERÓN; PFISTER; FRANÇA, 2015, p. 34). Na época, esta discussão aprofundou-se procurando estabelecer o papel social das instituições universitárias e então a relação destas com 
as avaliações. De acordo com Dias Sobrinho (2004), a avaliação da educação superior tem impactos sobre toda a sociedade, pois ultrapassa os âmbitos do objeto a que se dirige. $\mathrm{O}$ autor afirma que, com o passar do tempo, a opinião dos pesquisadores a respeito dos rankings mudou. No início dos anos 2000, os rankings eram vistos como um fenômeno negativo, relacionados à mídia e à regulação governamental. Alguns anos depois passaram a ser reconhecidos por ter a "[...] capacidade de gerar maior transparência e contribuir para o processo de melhoria da qualidade da educação." (DIAS SOBRINHO, 2004, p. 37).

Em concordância com a validade dos rankings, Calderón, Pfister e França (2015) argumentam que os rankings atestam o prestígio e o diferencial de uma instituição, servem como controle de qualidade por parte dos governos e como instrumentos que auxiliam na tomada de decisão em relação a qual universidade deve ser escolhida, dependendo do que se procura em uma instituição. Sendo assim, as classificações são interpretadas hoje como uma forma de competitividade global (HAZELKORN, 2019) e é inegável o impacto que possuem no comportamento das IES, sendo estes positivos e negativos (GOGLIO, 2016). Cerca de $60 \%$ das universidades europeias mantêm equipes dedicadas em tempo integral à análise do desempenho em rankings universitários, considerada uma questão vital na governança acadêmica. Cerca de $80 \%$ desses núcleos respondem diretamente às reitorias (MARCOVITCH, 2018).

Hazerlkorn, Loukkola e Zhang (2014) relatam que 93\% dos gestores em universidades europeias monitoram o desempenho dos rankings; $60 \%$ dedicam recursos humanos para tal fim, geralmente vinculados a unidades de planejamento estratégico ou coleta de dados; $85 \%$ reportam diretamente para o gabinete do reitor, ou equivalente; 39\% já tomaram alguma decisão administrativa, institucional ou acadêmica em resposta aos aprendizados dos rankings; e apenas $29 \%$ dizem que essas comparações não têm nenhum efeito no processo de tomada de decisão. Tais resultados refletem que em países europeus existe forte reconhecimento do posicionamento nos rankings (AXEL-BERG, 2018).

Apesar dos rankings já existirem no Brasil desde a década de 80 , a cultura de avaliação universitária vem ganhando espaço mais recentemente. Além dos tradicionais processos avaliativos realizados por órgãos governamentais, observa-se recentemente o interesse das universidades por conhecer e melhorar seus resultados nessas avaliações, como evidenciado em fóruns e publicações do Conselho de Reitores das Universidades Estaduais Paulistas (MARCOVITCH, 2018).

Em face da necessidade de maior conhecimento sobre os rankings, o projeto iniciado em 2016 procura ampliar a discussão sobre o tema ao pesquisar a avaliação das principais instituições brasileiras, as metodologias utilizadas pelos principais rankings universitários e identificar estratégias para melhorar o desempenho das IES (ALVES; DRESSLER; VANZ, 2019; VANZ, 2018; VANZ et al., 2018a, 2018b). Neste contexto, o presente artigo objetiva compreender e discutir as metodologias utilizadas por dois rankings distintos, o ranking internacional U-Multirank e o nacional Ranking Universitário Folha, buscando expandir a perspectiva de compreensão acerca do tema e aprofundar a discussão acerca destes rankings aqui no Brasil. A importância conquistada pelos rankings na sociedade atual torna imprescindível compreender os indicadores utilizados, se eles realmente levam em consideração o contexto brasileiro ou, a exemplo dos rankings internacionais, priorizam a atuação da universidade internacionalmente. As seções seguintes apresentam o histórico e a metodologia utilizada por cada um dos rankings, além dos resultados para as universidades brasileiras nas edições do ano de 2019. Algumas considerações finais encerram o trabalho. 


\section{PROCEDIMENTOS METODOLÓGICOS}

O estudo fundamenta-se em uma revisão de literatura sobre rankings universitários, especialmente o U-Multirank e o Ranking Universitário Folha. A pesquisa documental foi feita no website dos rankings para identificar o histórico e entender as metodologias utilizadas. Para análise do desempenho das instituições brasileiras foi feita, entre os meses de maio e novembro de 2019, a consulta às edições de 2020 do U-Multirank e 2018 e 2019 do Ranking Universitário Folha.

A pesquisa no UMR foi realizada a partir de consulta à plataforma, para fins de conhecimento das dimensões e indicadores que este ranking utiliza. No mês de junho de 2019, foi lançada a sexta edição do ranking. Em contato por e-mail (U-MULTIRANK, 2019d), a instituição responsável enviou às autoras uma planilha contendo os dados das universidades brasileiras, o que permitiu a checagem e comparação com os dados disponibilizados na plataforma online (U-MULTIRANK, 2019a). Todas as instituições brasileiras presentes no UMR com seus respectivos conceitos em cada indicador de desempenho institucional foram dispostas em uma planilha criada no software Excel. Esta planilha possibilitou a geração de gráficos e tabelas para melhor visualização do desempenho das universidades.

A pesquisa no RUF iniciou em maio de 2019 com consulta à edição 2018. Em 02 de outubro de 2019, foi lançada a edição 2019, com a classificação das instituições brasileiras e os indicadores avaliados. Procedeu-se a uma comparação entre as 20 melhores universidades conceituadas, buscando entender como os indicadores são utilizados e se a realidade regional de cada instituição é considerada. Por fim, confrontou-se no RUF a posição das universidades brasileiras presentes no UMR, visando à comparação entre o desempenho das mesmas em um ranking de abrangência nacional e outro internacional.

\section{U-MULTIRANK}

A ideia do U-Multirank surgiu em uma conferência da União Europeia em 2008, que exigia uma nova metodologia para medir as diferentes dimensões da excelência em instituições de ensino superior e pesquisa na Europa e em um contexto internacional. Partindo desse ponto, a Comissão Europeia encomendou um estudo de viabilidade para o desenvolvimento de um sistema de classificação multidimensional. Este estudo, concluído por um consórcio de organizações de ensino superior e pesquisa (conhecido como CHERPA) em 2011, confirmou que o conceito e a implementação adicional de um ranking multidimensional eram viáveis, com base no trabalho piloto com 150 instituições de ensino superior da Europa e em todo o mundo (U-MULTIRANK, 2019a).

O U-Multirank teve origem no estudo da Comissão Europeia e foi desenvolvido e implementado por iniciativa de um consórcio independente, liderado pelo professor Frans van Vught do Center for Higher Education Policy Studies (CHEPS) da University of Twente (Países Baixos), professor Frank Ziegele do Centre for Higher Education (CHE) (Alemanha), Centre for Science and Technology Studies (CWTS) da Leiden University (Países Baixos), e Foundation of Knowledge and Development (Fundacion CYD, Espanha). Atualmente, o U-Multirank é financiado pela Fundação Bertelsmann, Banco Santander e Programa Erasmust. O consórcio também trabalha em estreita colaboração com vários parceiros nacionais e partes interessadas no ranking (U-MULTIRANK, 2019a).

De acordo com Marcovitch (2018, p. 253), o UMR é uma "Iniciativa conjunta da comunidade europeia que enfatiza os processos de benchmarking e comparação qualificada 
entre universidades.". Sua publicação ocorre anualmente desde 2014 e em sua primeira publicação mais de 850 instituições de ensino superior e mais de 70 países foram incluídos. Hoje esse número cresceu exponencialmente e abrange mais de 1.700 universidades em 96 países (U-MULTIRANK, 2019a).

O U-Multirank abrange diversas tipologias de universidades, incluindo as técnicas, especializadas em música, universidades agrícolas, universidades de ciências aplicadas, além das universidades tradicionais que são mais voltadas para pesquisa. Seu público são estudantes, administradores de universidades, criadores de políticas, acadêmicos, líderes de negócios, entre outros. Além disso, este é um ranking gratuito para seus usuários e não há qualquer tipo de custos para a inclusão das instituições de ensino superior (U-MULTIRANK, 2019b). Isso ocorre, pois as instituições que fazem parte do mesmo financiam seus próprios custos operacionais para a coleta de dados, sendo que estas variam de acordo com a sofisticação dos seus próprios sistemas internos que realizam a coleta de dados e gerenciamento das mesmas. O site do U-Multirank disponibiliza um formulário para as universidades se inscreverem para inclusão no ranking.

\subsection{Metodologia utilizada pelo U-Multirank}

Diferententemente de outros rankings institucionais, o UMR não publica uma tabela geral de classificação (MARCOVITCH, 2018). Ele permite que o usuário desenvolva seu próprio ranking de universidades a partir da livre escolha dos indicadores de sua preferência, ou seja, ao invés de lançar uma lista pronta, o website do U-Multirank permite a criação da lista a partir dos interesses do usuário (U-MULTIRANK, 2019c). Neste sentido, o ranking apresenta-se como uma alternativa aos rankings já existentes, que utilizam instrumentos unidimensionais de avaliação e, com isso, falham na captura das diferenças e similaridades entre instituições (CAPES, 2019). No entanto, de acordo com Goglio (2016), o UMR, assim como os demais rankings, também possui limitações quando se trata da elaboração dos indicadores de pesquisa, pois a maior parte dos seus dados é proveniente de questionários, o que dificulta a sua validação. $O$ fornecimento de informações falsas pelas instituições de ensino para galgar melhores posições nos rankings é um problema reconhecido (RANIERI, 2018).

Por ser um ranking multidimensional, o U-Multirank não atesta a qualidade das instituições e/ou departamentos, pois parte do princípio que tal julgamento cabe ao usuário, seja ele aluno, instituição ou governo. Além disso, emprega método híbrido que consiste em dados bibliométricos provenientes de bases de dados e pesquisa de opinião com instituições, departamentos e alunos. Os dados que as universidades fornecem sobre si mesmas são cuidadosamente verificados e esse é um dos compromissos mais significativos do UMultirank. O processo de verificação inclui várias etapas e procedimentos: os dados são submetidos a vários testes estatísticos para consistência e plausibilidade; outliers e outros resultados surpreendentes são cuidadosamente verificados. O processo inclui verificações manuais e automatizadas e um processo contínuo de comunicação direta com as universidades (U-MULTIRANK, 2019b).

A plataforma utiliza cinco dimensões distintas de avaliação: (1) ensino e aprendizagem, (2) pesquisa, (3) transferência de conhecimento, (4) orientação internacional e (5) engajamento regional. Uma vez que os dados são coletados, a avaliação é feita a partir de grupos de ranqueamento, assim, a avaliação realizada fornece a posição de uma instituição em cinco grupos de desempenho que vai do "muito bom" ao "fraco" para cada um dos 36 indicadores utilizados na avaliação institucional (U-MULTIRANK, 2019a). Diferentemente dos 
demais rankings globais de universidades, o desempenho das instituições não é apresentado na forma de league tables. Ao invés disso, o UMR utiliza uma figura circular com raios que remete a um gráfico sunburst para ilustrar o perfil de desempenho da universidade. As variações no sombreamento simbolizam as cinco dimensões do U-Multirank, com os raios representando os indicadores individuais. Nesse gráfico, as pontuações de desempenho das instituições são agrupadas em cada indicador e representadas pelo comprimento dos raios correspondentes, assim, quanto maior o raio, melhor a instituição executa determinado indicador (FEDERKEIL et al., 2012). A Figura 1 a seguir compara uma instituição francesa (à esquerda) e uma brasileira (à direita):

Figura 1 - Exemplo de gráfico sunburst do U-Multirank 2020 para o desempenho individual de universidades
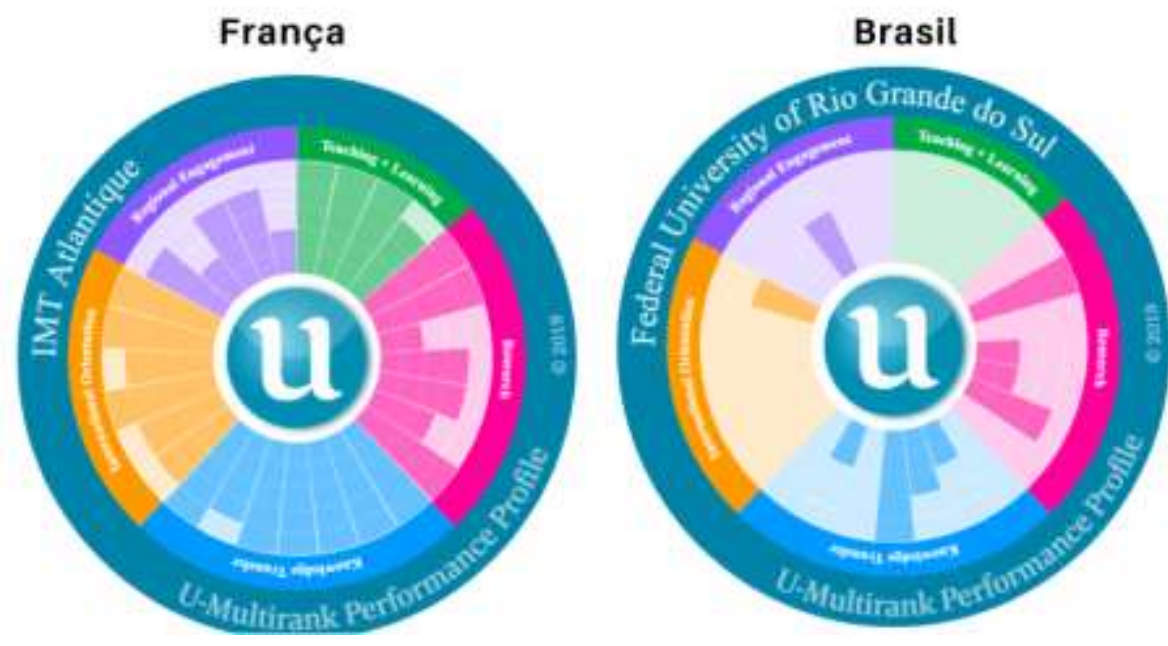

Fonte: U-Multirank (2019a).

A avaliação institucional baseia-se em dados provenientes de bases de dados e questionários enviados pelas universidades. Além disso, esse ranking também realiza comparações entre universidades que possuem alguma similaridade, como também comparações entre algumas áreas específicas, os quais obtêm suas informações através de bases de dados, questionários departamentais e pesquisa com alunos. No entanto, neste tipo de comparação não são computados os conceitos para o desempenho institucional no todo, apenas é possível de serem apurados quando a pesquisa realizada pelo usuário é restrita a determinado assunto/área. O Quadro 1 apresenta os indicadores de desempenho institucional do UMultinrank, assim como sua forma de coleta de dados. Tais dados são provenientes da sexta edição desse ranking e estão disponíveis para consulta na sua plataforma: https://www.umultirank.org/.

O U-Multirank utiliza indicadores tradicionais, no entanto, inova ao valorizar indicadores de interação universidade-mercado-sociedade, por exemplo, Strategic research partnerships, Professional publications, Income from private sources, Co-publications with industrial partners. $\mathrm{O}$ engajamento regional é valorizado e mensurado através de indicadores de interação das atividades e ex-alunos que trabalham na região onde se situa a universidade, como Bachelor graduates working in the region, Master graduates working in the region, Student internships in the region, Strategic research partnerships in the region. Esta é, sem dúvida, a dimensão de avaliação que diferencia o U-Multirank dos demais, considerando-se que este tipo de indicador não é avaliado por outros rankings internacionais. 
Quadro 1 - Dimensões, indicadores e fonte dos dados do U-Multirank edição 2020

\begin{tabular}{|c|c|c|}
\hline Dimensões & Indicadores & Fonte dos dados \\
\hline \multirow{4}{*}{$\begin{array}{l}\text { Ensino e aprendizagem } \\
\text { [Teaching \& learning] }\end{array}$} & $\begin{array}{l}\text { Taxa de formação de bacharelado } \\
\text { [Bachelor graduation rate] }\end{array}$ & Questionário Institucional \\
\hline & $\begin{array}{l}\text { Taxa de formação no mestrado } \\
\text { [Masters graduation rate] }\end{array}$ & Questionário Institucional \\
\hline & $\begin{array}{l}\text { Formação no tempo (bacharelado) } \\
\text { [Graduating on time (bachelors)] }\end{array}$ & Questionário Institucional \\
\hline & $\begin{array}{l}\text { Formação no tempo (mestrado) } \\
\text { [Graduating on time (masters)] }\end{array}$ & Questionário Institucional \\
\hline \multirow{10}{*}{$\begin{array}{l}\text { Pesquisa } \\
\text { [Research] }\end{array}$} & $\begin{array}{l}\text { Renda de pesquisa externa } \\
\text { [External research income] }\end{array}$ & Questionário Institucional \\
\hline & $\begin{array}{l}\text { Publicações relacionadas à arte } \\
\text { [Art related output] }\end{array}$ & Questionário Institucional \\
\hline & $\begin{array}{l}\text { Posições pós-doc } \\
\text { [Post-doc positions] }\end{array}$ & Questionário Institucional \\
\hline & $\begin{array}{l}\text { Publicações profissionais } \\
\text { [Professional publications] }\end{array}$ & Questionário Institucional \\
\hline & $\begin{array}{l}\text { Parcerias estratégicas de pesquisa } \\
\text { [Strategic research partnerships] }\end{array}$ & Questionário Institucional \\
\hline & $\begin{array}{l}\text { Taxa de citação } \\
\text { [Citation rate] }\end{array}$ & $\begin{array}{l}\text { CWTS/Thomson Reuters - Web of Science } \\
\text { Core Collection }\end{array}$ \\
\hline & $\begin{array}{l}\text { Publicações de pesquisa (números } \\
\text { absolutos) } \\
\text { [Research publications (absolute num- } \\
\text { bers)] }\end{array}$ & $\begin{array}{l}\text { CWTS/Thomson Reuters - Web of Science } \\
\text { Core Collection }\end{array}$ \\
\hline & $\begin{array}{l}\text { Publicações de pesquisa (tamanho } \\
\text { normalizado) } \\
\text { [Research publications (size- } \\
\text { normalised)] }\end{array}$ & $\begin{array}{l}\text { CWTS/Web of Science } \\
\text { external sources (IAU database; internet) }\end{array}$ \\
\hline & $\begin{array}{l}\text { Publicações mais citadas } \\
\text { [Top cited publications] }\end{array}$ & $\begin{array}{l}\text { CWTS/Thomson Reuters - Web of Science } \\
\text { Core Collection }\end{array}$ \\
\hline & $\begin{array}{l}\text { Publicações interdisciplinares } \\
\text { [Interdisciplinary publications] }\end{array}$ & $\begin{array}{l}\text { CWTS/Thomson Reuters - Web of Science } \\
\text { Core Collection }\end{array}$ \\
\hline \multirow{2}{*}{$\begin{array}{l}\text { Transferência de co- } \\
\text { nhecimento } \\
\text { [Knowledge transfer] }\end{array}$} & $\begin{array}{l}\text { Renda de fontes privadas } \\
\text { [Income from private sources] }\end{array}$ & Questionário Institucional \\
\hline & $\begin{array}{l}\text { Spin-offs } \\
\text { [Spin-offs] }\end{array}$ & Questionário institucional \\
\hline
\end{tabular}




\begin{tabular}{|c|c|c|}
\hline & $\begin{array}{l}\text { Renda do desenvolvimento profissional } \\
\text { contínuo } \\
\text { [Income from continuous professional } \\
\text { development] }\end{array}$ & Questionário institucional \\
\hline & $\begin{array}{l}\text { Empresas de pós graduação } \\
\text { [Graduate Companies] }\end{array}$ & Questionário institucional \\
\hline & $\begin{array}{l}\text { Co-publicações com parceiros industri- } \\
\text { ais } \\
\text { [Co-publications with industrial } \\
\text { partners] }\end{array}$ & $\begin{array}{l}\text { CWTS/Thomson Reuters - Web of Science } \\
\text { Core Collection }\end{array}$ \\
\hline & $\begin{array}{l}\text { Patentes concedidas (números absolu- } \\
\text { tos) } \\
\text { [Patents awarded (absolute numbers)] }\end{array}$ & CWTS/PATSTAT database \\
\hline & $\begin{array}{l}\text { Patentes concedidas (tamanho norma- } \\
\text { lizado) } \\
\text { [Patents awarded (size-normalised)] }\end{array}$ & CWTS/PATSTAT database \\
\hline & $\begin{array}{l}\text { Co-patentes da indústria } \\
\text { [Industry co-patents] }\end{array}$ & CWTS/PATSTAT database \\
\hline & $\begin{array}{l}\text { Publicações citadas em patentes } \\
\text { [Publications cited in patents] }\end{array}$ & $\begin{array}{l}\text { CWTS/Thomson Reuters - Web of Science } \\
\text { Core Collection }\end{array}$ \\
\hline \multirow{6}{*}{$\begin{array}{l}\text { Orientação internacio- } \\
\text { nal } \\
\text { [International orienta- } \\
\text { tion] }\end{array}$} & $\begin{array}{l}\text { Licenciatura em língua estrangeira } \\
\text { [Foreign language bachelor program- } \\
\text { mes] }\end{array}$ & Questionário institucional \\
\hline & $\begin{array}{l}\text { Programas de mestrado em língua } \\
\text { estrangeira } \\
\text { [Foreign language master program- } \\
\text { mes] }\end{array}$ & Questionário institucional \\
\hline & $\begin{array}{l}\text { Mobilidade do aluno } \\
\text { [Student mobility] }\end{array}$ & Questionário institucional \\
\hline & $\begin{array}{l}\text { Equipe acadêmica internacional } \\
\text { [International academic staff] }\end{array}$ & Questionário institucional \\
\hline & $\begin{array}{l}\text { Doutorado internacional } \\
\text { [International doctorate degrees] }\end{array}$ & Questionário institucional \\
\hline & $\begin{array}{l}\text { Publicações conjuntas internacionais } \\
\text { [International joint publications] }\end{array}$ & $\begin{array}{l}\text { CWTS/Thomson Reuters - Web of Science } \\
\text { Core Collection }\end{array}$ \\
\hline \multirow{3}{*}{$\begin{array}{l}\text { Engajamento regional } \\
\text { [Regional engagement] }\end{array}$} & $\begin{array}{l}\text { Graduados que trabalham na região } \\
\text { [Bachelor graduates working in the } \\
\text { region] }\end{array}$ & Questionário institucional \\
\hline & $\begin{array}{l}\text { Mestres que trabalham na região } \\
\text { [Master graduates working in the re- } \\
\text { gion] }\end{array}$ & Questionário institucional \\
\hline & Estágios estudantis na região & Questionário institucional \\
\hline
\end{tabular}




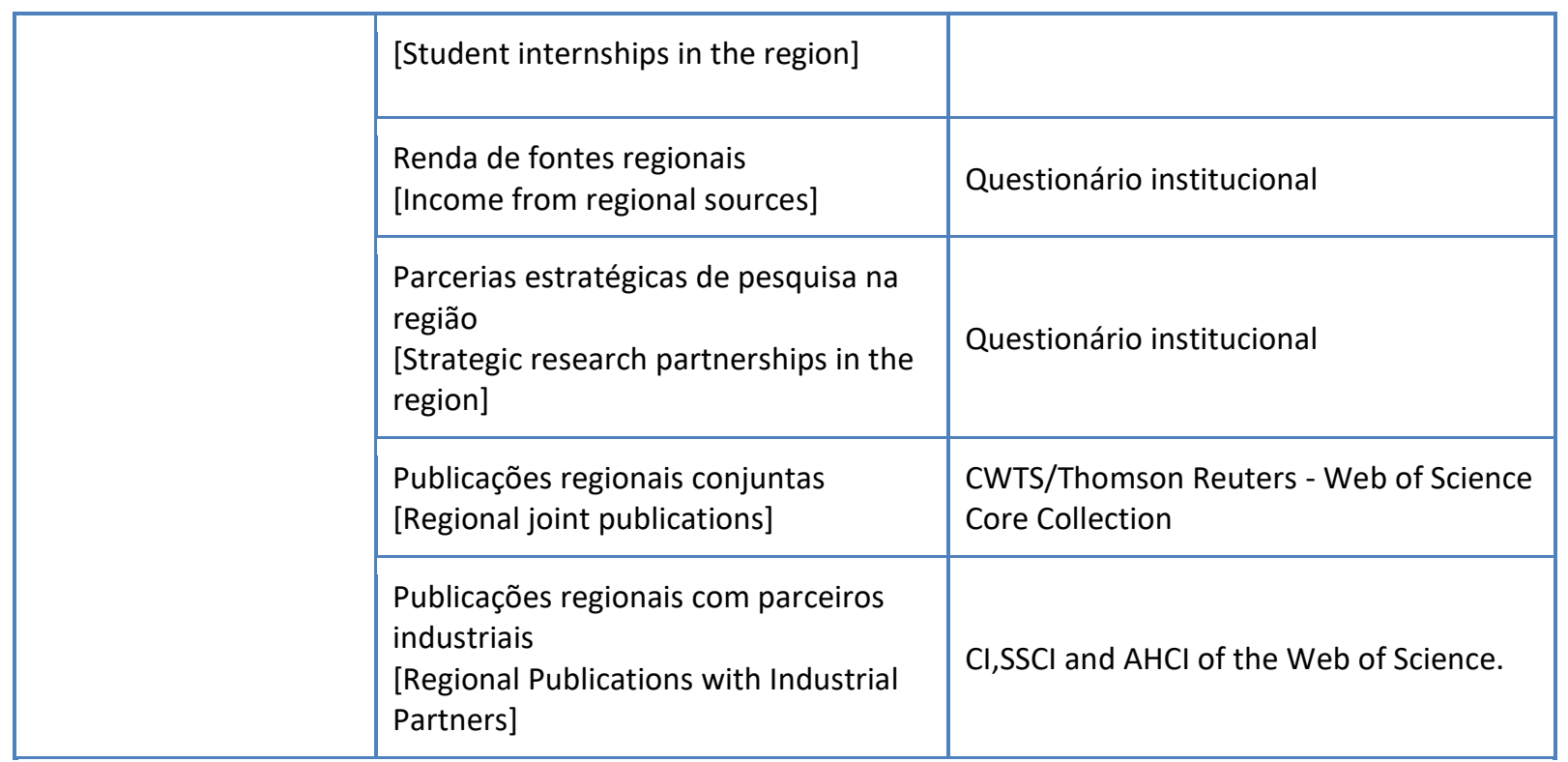

Fonte: Elaborado pelas autoras (2020).

Observa-se que, dos 36 indicadores de desempenho utilizados pelo U-Multirank para avaliar as universidades, $63,8 \%$ são provenientes de questionários e o restante $(36,2 \%)$ provém de bases de dados como CWTS/Clarivate - Web of Science Core Collection, CWTS/PATSTAT, ETER e IPEDS. O indicador Ensino e Aprendizagem advém inteiramente de questionários, enquanto Engajamento Regional e Orientação Internacional contam com esta fonte majoritariamente ( $71 \%$ e $83 \%$, respectivamente). A Figura 2 ainda demonstra que mesmo os outros dois indicadores, quais sejam, Transferência de Conhecimento e Pesquisa, também têm forte apelo qualitativo.

Figura 2 - Dimensões de avaliação do U-Multirank em relação à origem dos dados

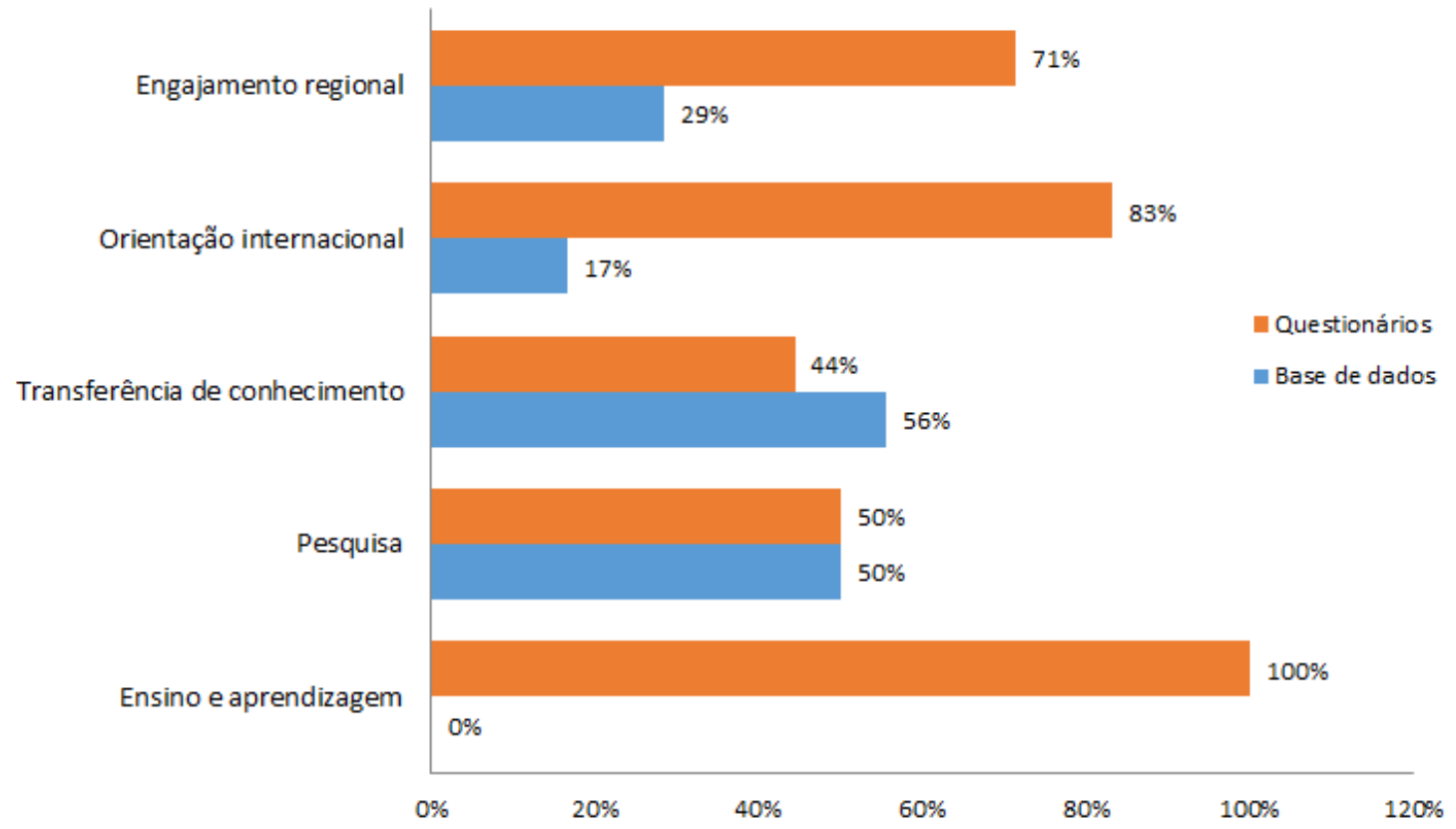

Fonte: Elaborado pelas autoras (2020). 
Após o entendimento das dimensões e indicadores do U-Multirank é possível analisar o desempenho das instituições brasileiras na sexta edição desse ranking internacional.

\subsection{Universidades Brasileiras no U-Multirank edição 2020}

As 15 universidades brasileiras presentes na sexta edição do U-Multirank são: Universidade de Brasília (UNB), Universidade Estadual de Campinas (UNICAMP), Universidade Federal do Ceará (UFC), Universidade Federal Fluminense (UFF), Universidade Federal do Mato Grosso (UFMT), Universidade Federal de Minas Gerais (UFMG), Universidade Federal do Paraná (UFPR), Universidade Estadual Paulista (UNESP), Universidade Federal de Pernambuco (UFPE), Universidade Federal do Rio Grande do Sul (UFRGS), Universidade Federal do Rio de Janeiro (UFRJ), Universidade Federal de Santa Catarina (UFSC), Universidade Federal de São Paulo (UNIFESP), Universidade de São Paulo (USP) e Universidade de São Carlos (UFSCAR).

Atualmente 17 universidades estão cadastradas neste ranking, no entanto as universidades do Estado do Rio de Janeiro (UERJ) e a Universidade Federal de Viçosa (UFV) ainda não possuem conceitos nos indicadores de desempenho, não sendo possível compará-las com outras IES.

O Quadro 2 apresenta o conceito de cada universidade brasileira cadastrada no UMR, em cada um dos 36 indicadores de desempenho institucional.

Os grupos são ranqueados observando-se a distância da pontuação de uma instituição da média daquele indicador para todas as instituições consideradas, ou seja, esses grupos são definidos em termos da distância de uma instituição da mediana. Todavia, não são calculadas as médias das pontuações, nem se estabelece um peso aos indicadores para somá-los e assim produzir um resultado único, pois de acordo com a metodologia utilizada por este ranking não se justifica a utilização de pontuações compostas, pois a mesma prejudica compreensão da diversidade e da qualidade das instituições e tende a exagerar diferenças de desempenho entre as mesmas (U-MULTIRANK, 2019a). Os conceitos são atribuídos conforme a variação da mediana de cada indicador, como apresentado a seguir:

a) Grupo A - Se o valor do indicador estiver acima da mediana mais $25 \%$ : valor $>$ mediana $+25 \%$

b) Grupo B - Se o valor do indicador for menor ou igual à mediana +25 e maior que a mediana:

$$
\text { mediana }+25 \% \geq \text { valor }>\text { mediana }
$$

c) Grupo $\mathrm{C}$ - Se o valor do indicador for menor ou igual à mediana e maior que a mediana menos $25 \%$ :

$$
\text { mediana } \geq \text { valor }>\text { mediana }-25 \%
$$

d) Grupo D - Se o valor do indicador for menor ou igual à mediana - $25 \%$ e acima de zero:

$$
\text { mediana }-25 \% \geq \text { valor }>0
$$

e) Grupo E - Se o valor do indicador é zero:

$$
\text { valor }=0
$$

Dessa forma, se a mediana de um indicador for de $60 \%$, ficarão com conceitos " $A$ " aqueles com valores acima de $75 \%$, conceitos " $B$ " entre $60 \%$ e $74,99 \%$, conceitos " $C$ " entre $45 \%$ a $59,99 \%$, conceitos " $D$ " aqueles com valores entre $0 \%$ e $44,99 \%$ e, por fim, conceitos "E" aqueles com $0 \%$. 
Quadro 2 - Conceitos individuais das universidades brasileiras no U-Multirank edição 2020

\begin{tabular}{|c|c|c|c|c|c|c|c|c|c|c|c|c|c|c|c|c|}
\hline & & UFC & UFF & UFMG & UFMT & UFPE & UFPR & UFRGS & UFRJ & UFSC & Ufscar & UnB & Unesp & Unicamp & Unifesp & Usp \\
\hline \multirow{4}{*}{ 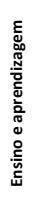 } & $\begin{array}{l}\text { Bachelor graduation } \\
\text { rate }\end{array}$ & D & - & - & D & - & - & - & - & - & - & - & - & B & - & B \\
\hline & Masters graduation rate & B & - & - & B & - & - & - & - & - & - & - & B & B & - & B \\
\hline & $\begin{array}{l}\text { Graduating on time } \\
\text { (bachelors) }\end{array}$ & B & - & - & - & - & - & - & - & - & - & - & A & - & - & - \\
\hline & $\begin{array}{l}\text { Graduating on time } \\
\text { (masters) }\end{array}$ & B & - & - & - & - & $\cdot$ & - & - & - & - & - & A & - & - & - \\
\hline \multirow{10}{*}{ 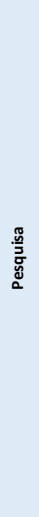 } & $\begin{array}{l}\text { External research } \\
\text { income }\end{array}$ & c & - & - & - & - & - & - & - & - & - & - & - & A & - & A \\
\hline & Art related output & - & - & - & D & - & - & - & - & - & - & - & c & - & - & - \\
\hline & Post-doc positions & - & - & - & D & - & - & - & - & - & - & - & A & A & - & - \\
\hline & $\begin{array}{l}\text { Professional publica- } \\
\text { tions }\end{array}$ & - & - & - & B & $\cdot$ & - & - & - & - & - & - & - & $\cdot$ & - & - \\
\hline & $\begin{array}{l}\text { Strategic research } \\
\text { partnerships }\end{array}$ & - & - & - & D & - & - & - & - & - & - & - & - & - & - & - \\
\hline & Citation rate & D & $\mathrm{D}$ & D & D & D & D & D & c & c & D & D & D & c & D & c \\
\hline & $\begin{array}{l}\text { Research publications } \\
\text { (absolute numbers) }\end{array}$ & B & B & B & B & B & B & B & B & B & B & B & A & B & B & A \\
\hline & $\begin{array}{l}\text { Research publications } \\
\text { (sizenormalised) }\end{array}$ & c & $\mathrm{D}$ & B & D & c & B & A & B & c & A & c & A & A & A & A \\
\hline & Top cited publications & D & $\mathrm{D}$ & D & D & D & D & D & D & D & D & D & D & D & D & D \\
\hline & $\begin{array}{l}\text { Interdisciplinary } \\
\text { publications }\end{array}$ & A & B & B & B & A & c & B & B & A & B & c & B & B & B & B \\
\hline \multirow{9}{*}{ 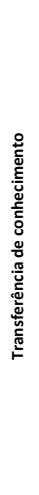 } & $\begin{array}{l}\text { Income from private } \\
\text { sources }\end{array}$ & D & - & - & - & - & - & - & - & - & - & - & - & c & - & D \\
\hline & Spin-offs & - & - & - & - & - & - & - & - & - & - & - & D & D & - & A \\
\hline & $\begin{array}{l}\text { Income from continuous } \\
\text { professional deve- } \\
\text { lopment }\end{array}$ & - & - & - & - & - & - & - & - & - & - & - & - & D & - & D \\
\hline & Graduate Companies & - & - & - & - & - & - & - & - & - & - & - & - & A & - & - \\
\hline & $\begin{array}{l}\text { Co-publications with } \\
\text { industrial partners }\end{array}$ & D & $\mathrm{D}$ & D & D & D & D & D & c & D & D & D & D & D & D & D \\
\hline & $\begin{array}{l}\text { Patents awarded } \\
\text { (absolute numbers) }\end{array}$ & E & $\mathrm{E}$ & c & $\mathrm{E}$ & D & $\mathrm{E}$ & D & c & c & D & $\mathrm{E}$ & D & c & D & D \\
\hline & $\begin{array}{l}\text { Patents awarded } \\
\text { (sizenormalised) }\end{array}$ & E & E & c & E & D & E & c & c & c & c & E & D & c & c & D \\
\hline & Insdustry co-patents & $x$ & $\mathrm{x}$ & c & $\mathrm{x}$ & E & $\mathrm{x}$ & A & A & A & E & $\mathrm{x}$ & A & A & A & c \\
\hline & $\begin{array}{l}\text { Publication cited in } \\
\text { patents }\end{array}$ & D & $\mathrm{D}$ & c & D & D & D & D & c & D & D & D & D & c & B & D \\
\hline \multirow{6}{*}{ 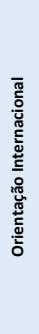 } & $\begin{array}{l}\text { Foreign language } \\
\text { bachelor programmes }\end{array}$ & E & - & - & E & - & - & - & - & - & - & - & E & - & - & - \\
\hline & $\begin{array}{l}\text { Foreign language master } \\
\text { programmes }\end{array}$ & - & - & - & $\mathrm{E}$ & - & - & - & - & - & - & - & $\mathrm{E}$ & - & - & - \\
\hline & Student mobility & D & - & - & D & - & - & - & - & - & - & - & c & c & - & B \\
\hline & $\begin{array}{l}\text { International academic } \\
\text { staff }\end{array}$ & D & - & - & D & - & - & - & - & - & - & - & D & D & - & D \\
\hline & $\begin{array}{l}\text { International doctorate } \\
\text { degrees }\end{array}$ & A & - & - & - & - & - & - & - & - & - & - & D & D & - & D \\
\hline & $\begin{array}{l}\text { International joint } \\
\text { publications }\end{array}$ & D & D & D & D & c & D & c & c & c & D & c & D & c & D & c \\
\hline \multirow{7}{*}{ 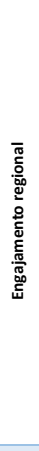 } & $\begin{array}{l}\text { Bachelor graduates } \\
\text { working in the region }\end{array}$ & - & - & - & - & - & - & - & - & - & - & - & - & - & - & - \\
\hline & $\begin{array}{l}\text { Master graduates } \\
\text { working in the region }\end{array}$ & - & - & - & - & - & - & - & - & - & - & - & - & - & - & - \\
\hline & $\begin{array}{l}\text { Student internships in } \\
\text { the region }\end{array}$ & A & - & - & - & - & - & - & - & - & - & - & A & - & - & - \\
\hline & $\begin{array}{l}\text { Income from regional } \\
\text { sources }\end{array}$ & - & - & - & - & - & - & - & - & - & - & - & - & - & - & - \\
\hline & $\begin{array}{l}\text { Strategic research } \\
\text { partnerships in the } \\
\text { region }\end{array}$ & - & - & - & - & - & - & - & - & - & - & - & A & - & - & - \\
\hline & $\begin{array}{l}\text { Regional joint } \\
\text { publications }\end{array}$ & B & A & c & D & B & c & c & A & D & B & B & c & D & A & c \\
\hline & $\begin{array}{l}\text { Regional Publications } \\
\text { with Industrial Partners }\end{array}$ & D & A & c & D & D & D & D & A & D & D & D & c & c & A & c \\
\hline & Legenda & \multicolumn{2}{|c|}{ A (muito bom) } & \multicolumn{2}{|l|}{ B (bom) } & \multicolumn{2}{|c|}{ C (média) } & \multicolumn{3}{|c|}{ D (abaixo da média) } & \multicolumn{2}{|l|}{$E$ (fraco) } & \multicolumn{2}{|c|}{ - (dados indisponiveis) } & \multicolumn{2}{|c|}{ X (não aplicável) } \\
\hline
\end{tabular}

Fonte: Elaborado pelas autoras (2020).

A análise dos dados quantitativos provenientes de bases de dados, que perfazem $33 \%$ dos indicadores do U-Multirank, revela que as instituições brasileiras possuem um conceito "bom" nos indicadores de Pesquisa, e "abaixo da média" em Transferência de conhe- 
cimento, Orientação internacional e Engajamento Regional. Por outro lado, os dados qualitativos, que compõem $67 \%$ do ranking e são provenientes dos questionários, tem conceito atribuído para apenas cinco universidades: UNICAMP, com $47,8 \%$ de conceitos atribuídos, UNESP $(56,5 \%)$, USP $(39,1 \%)$, UFMT $(43,5 \%)$ e UFC $(47,8 \%)$. Observa-se que destas cinco IES, três são paulistas, o que pode indicar os resultados positivos do movimento para entender e trabalhar em prol dos rankings universitários, declarado pelo Conselho de Reitores das Universidades Paulistas (MARCOVITCH, 2018).

Os conceitos atribuídos pelo U-Multirank reiteram resultados de outros rankings no que diz respeito à produção científica (VANZ, 2018). Em geral, as universidades brasileiras têm alta produção científica, conforme grande volume de conceitos B atribuídos a todas as 15 IES no indicador Research Publication. O mesmo indicador, quando normalizado pelo tamanho institucional, demonstra desempenho ainda melhor, considerando grande volume de conceitos A. No entanto, as universidades brasileiras possuem em sua maioria conceitos "abaixo da média" nos indicadores Citation rate e Top cited publications que são provenientes de bases de dados internacionais. O idioma, apesar de não ser um indicador oficial dos rankings universitários, é apontado na literatura como um grande influenciador, visto que os resultados de pesquisas que são publicados em idiomas que não seja o inglês possuem menos visibilidade e, consequentemente, poucas citações.

O Quadro 2 mapeia os indicadores que têm seu conceito decorrente de coleta em bases de dados: visualiza-se conceito para todas as universidades brasileiras, variando do $\mathrm{A}$ (muito bom), B (bom), C (média), D (abaixo da média) ao E (fraco). São eles: Citation rate, Research publications (absolute numbers), Research publications (size-normalised), Top cited publications, Interdisciplinary publications, Co-publications with industrial partners, Patents awarded (absolute numbers), Patents awarded (size-normalized), Industry co-patents, Publications cited in patents, International joint publications, Regional joint publications, Regional Publications with Industrial Partners. No entanto, observa-se a falta de conceitos para os indicadores que se fundamentam em coleta de dados por questionário, levando à inferência de que as IES brasileiras não respondem/enviam os questionários ao U-Multirank.

A Figura 3 apresenta a síntese da situação - as barras na cor laranja correspondem ao total de dados indisponíveis.

Figura 3 - Síntese de conceitos individuais das universidades brasileiras no U-Multirank 2020

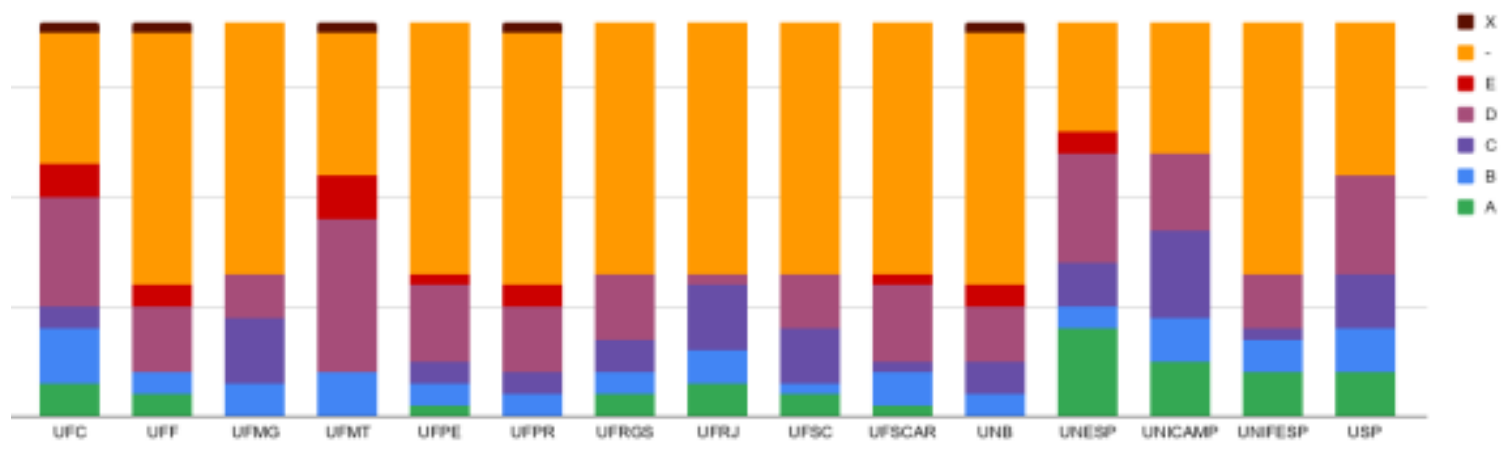

Fonte: Elaborado pelas autoras (2020).

Observa-se para a maioria das universidades uma grande barra laranja, indicando a possível "não resposta" ao questionário. Estes indicadores qualitativos, que poderiam ser positivos para as universidades brasileiras poderem expressar suas atividades regionais em razão de questões como idioma, acaba por ser o fator que as colocam com uma média ruim 
nos indicadores. Tal discrepância é evidenciada no gráfico sunburst (Figura 1), em que a IES brasileira apresentada possui vários campos em branco em comparação com a instituição francesa. Tais campos referem-se aos indicadores qualitativos, visto que tal universidade apresenta "dados indisponíveis" em todos os indicadores provenientes de questionário.

Apenas cinco universidades brasileiras possuem conceito atribuído em alguns dos indicadores qualitativos: UNICAMP, UNESP, USP, UFMT e UFC. Depreende-se que, das quatro universidades paulistas cadastradas neste ranking, três delas possuem a barra de "dados indisponíveis" menores, apesar de nenhuma delas possuir o objetivo de subir posições nos rankings internacionais como algo estabelecido em suas metas de acordo com o Plano de Desenvolvimento Institucional (PDI) de cada universidade, conforme demonstra pesquisa realizada por Alves, Dressler e Vanz (2019), assim como a UFMT. Por outro lado, a UFC declara que possui a intenção de melhorar suas posições nos rankings acadêmicos internacionais.

\section{RUF}

Apesar da discussão sobre rankings surgir no Brasil a partir de 1990, em 1982 é publicado o primeiro ranking universitário nacional pela revista Playboy, chamado "Ranking MeIhores Universidades", que alcançou destaque devido à falta de outros rankings privados ou estatais (CALDERÓN; MATIAS; LOURENÇO, 2014). Em seguida, o Guia do Estudante teve sua primeira publicação em 1984 e passou a classificar as melhores universidades a partir de 1988 (CALDERÓN; LOURENÇO, 2017). Somente em 1996 surge a primeira iniciativa governamental brasileira através do "Provão", que previa o ranqueamento dos cursos oferecidos por instituições de educação superior "[...] amplamente divulgado pelos meios de comunicação e elaborado a partir do desempenho dos estudantes." (CALDERÓN; LOURENÇO, 2017, p. 95).

Em 14 de abril de 2004, a Lei № 10.861 institui o Sistema Nacional de Avaliação da Educação Superior (SINAES), com o objetivo inicial de avaliar as instituições para conhecer o perfil e a atuação de cada uma, sem estabelecer uma classificação (BRASIL, 2004). Esta finalidade se altera em 2008 com a inclusão do Índice Geral de Cursos e do Conceito Preliminar de Curso, que permitem uma classificação típica dos rankings privados conhecidos até então. Da mesma forma, em 2012 o RUF começou a avaliar as instituições brasileiras.

O RUF é uma avaliação anual de todas as universidades brasileiras ativas, entre públicas e privadas, com cursos presenciais e não tecnólogos. Além das universidades, são avaliadas as $\mathbf{4 0}$ graduações com mais ingressantes no Brasil. O ranking de cursos considera também faculdades e centros universitários. Todas as universidades brasileiras são avaliadas pelo RUF sem que haja necessidade de inscrição da instituição para tal. O resultado é apresentado no mês de outubro de cada ano, através de uma lista de classificação geral e também pela classificação dos indicadores individualmente.

O ranking é mantido pelo jornal Folha de São Paulo e está sob a responsabilidade de uma equipe formada por uma jornalista e um conselho consultivo, além de contar com uma equipe de apuração dos dados. A partir de 2012, o RUF passou a movimentar aproximadamente quatro milhões de dados sobre as universidades, centros universitários e faculdades brasileiras, tornando-se a maior compilação de informações sobre o ensino superior já existente no país (RIGHETTI, 2016).

Em sua primeira edição, foram contemplados quatro indicadores visando avaliar ensino, pesquisa, inovação e empregabilidade dos egressos. A partir de 2013, o RUF passou a considerar também a internacionalização das universidades, demonstrando a atualidade dos 
indicadores e a aderência às diretrizes nacionais. Segundo o Plano Nacional de Pósgraduação (PNPG) 2011-2020, editado pela Coordenação de Aperfeiçoamento de Pessoal de Nível Superior (CAPES), a Internacionalização permanece como uma das metas principais do Plano, objetivando criar diferentes programas para atrair mais estudantes e docentes ao Brasil, assim como enviar estudantes para fazer doutorado em outros países e, ainda, aumentar o número de publicações brasileiras em parceria com instituições estrangeiras. (CAPES, 2010a).

\subsection{Metodologia utilizada pelo RUF}

O RUF avalia todas as universidades do país, sendo que a edição 2019 aponta 197 instituições. A avaliação é feita através de cinco indicadores que se subdividem em 17 componentes. Cada indicador gera uma nota individual e a soma dos cinco estabelece uma classificação geral, conforme Quadro 3. Há também uma classificação por indicador, apontando qual universidade pontua mais em cada quesito.

Quadro 3 - Indicadores, componentes, peso e fonte dos dados utilizados pelo RUF 2019

\begin{tabular}{|c|c|c|c|c|}
\hline Indicador & Peso & Componentes do Indicador & Peso & Fonte \\
\hline \multirow{8}{*}{ Pesquisa } & \multirow{8}{*}{$42 \%$} & Total de publicações & $7 \%$ & Web of Science \\
\hline & & Total de citações & $7 \%$ & Web of Science \\
\hline & & Citações por publicação & $4 \%$ & Web of Science \\
\hline & & Publicações por docente & $7 \%$ & Web of Science \\
\hline & & Publicações em revistas nacionais & $3 \%$ & SciELO \\
\hline & & Recursos recebidos por instituição & $3 \%$ & Inep-MEC \\
\hline & & Bolsistas CNPq & $2 \%$ & CNPq \\
\hline & & Teses & $2 \%$ & CNPq \\
\hline \multirow{4}{*}{ Ensino } & \multirow{4}{*}{$32 \%$} & Opinião de docentes & $20 \%$ & Pesquisa de opinião \\
\hline & & Professores com doutorado e mestrado & $4 \%$ & Inep-MEC \\
\hline & & Professores em dedicação integral e parcial & $4 \%$ & Inep-MEC \\
\hline & & Nota no Enade & $4 \%$ & Enade \\
\hline Mercado & $18 \%$ & Opinião de empregadores sobre preferências de contratação & $18 \%$ & Pesquisa de opinião \\
\hline \multirow{2}{*}{ Internacionalização } & \multirow{2}{*}{$4 \%$} & Citações internacionais por docente & $2 \%$ & Web of Science \\
\hline & & Publicações em coautoria internacional & $2 \%$ & Web of Science \\
\hline \multirow{2}{*}{ Inovação } & \multirow{2}{*}{$4 \%$} & Patentes & $2 \%$ & INPI \\
\hline & & Parceria com empresas & $2 \%$ & INPI \\
\hline
\end{tabular}

Fonte: Elaborado pelas autoras (2020).

Nota: SciELO (Scientific Electronic Library Online); Inep-MEC (Instituto Nacional de Estudos e Pesquisas Educacionais Anísio Teixeira-Ministério da Educação); CNPq (Conselho Nacional de Desenvolvimento Científico e Tecnológico); Enade (Exame Nacional de Desempenho dos Estudantes); INPI (Instituto Nacional da Propriedade Industrial). 
O indicador Mercado, responsável por $18 \%$ da nota final, é extraído totalmente de pesquisas de opinião realizadas pelo Datafolha. A edição 2019 do ranking contou com a opinião de 5.549 profissionais de Recursos Humanos, que opinaram sobre as suas preferências de contratação, de 2017 a 2019. Estes profissionais são consultados em todos os estados do Brasil, o que permite um resultado diversificado (RIGHETTI, 2020).

As universidades brasileiras fundamentam-se na tríade ensino-pesquisa-extensão. Assim, ao compor $74 \%$ da nota com os indicadores Pesquisa e Ensino, o RUF se aproxima da realidade das universidades brasileiras. Além disso, 20\% do indicador Ensino é composto por pesquisa de opinião realizada pelo Instituto de Pesquisas Datafolha, que consulta docentes em todos os estados do Brasil. O resultado apresentado no ranking 2019 contempla as pesquisas realizadas nos três últimos anos, somando assim a avaliação total de 2.309 docentes (RIGHETTI, 2020).

O uso de dados extraídos da SciELO, biblioteca eletrônica nacional, valoriza a produção brasileira, fornecendo um caráter local à avaliação. Os dados da SciELO complementam os dados internacionais coletados na Web of Science para os indicadores Total de publicações, Total de citações, Citações por publicação e Publicações por docente.

Os rankings internacionais consideram dados de produção científica das bases de dados internacionais Web of Science e SCOPUS, o que não representa de forma completa a realidade brasileira, já que há uma pequena quantidade de periódicos brasileiros indexados nestas bases de dados. Da mesma forma, há vários temas que são publicados tradicionalmente em periódicos nacionais, e assim, ao se levar em conta apenas publicações internacionais, as publicadas nacionalmente não são consideradas relevantes (STREHL et al., 2016).

O RUF avalia todas as instituições brasileiras, considerando assim o contexto das mesmas, ao analisar as publicações nacionais além das internacionais, a opinião de empregadores sobre preferências de contratação e o número de patentes requeridas pela instituição. Porém, a maioria dos indicadores do ranking utiliza números totais, diferentemente de rankings internacionais como o ARWU que relativiza o tamanho das instituições (VANZ, 2018). Esta metodologia estabelecida pelo RUF pode ser percebida como um ponto vulnerável na composição da classificação geral, afinal, para indicadores como Total de publicações e Bolsistas CNPq o tamanho da instituição influencia nos resultados.

\subsection{Universidades Brasileiras no RUF edição 2019}

A edição 2019 do RUF classifica 197 IES. Nas 20 primeiras posições, aparecem IES de 11 estados diferentes, o que demonstra existência de uma distribuição parcial das universidades brasileiras de qualidade. Nota-se a ausência de instituições da região norte do Brasil, o que revela assimetria regional e justifica a criação, pela CAPES, de programas Minter e Dinter e outros como o "Acelera Amazônia", idealizado para ampliar o número de pesquisadores e grupos de pesquisa na região e citado no PNPG 2011-2020 (CAPES, 2010b). Entre as 20 primeiras posições, o estado de São Paulo é o que mais classifica instituições (25\%), sendo que duas universidades estaduais paulistas (USP e UNICAMP) ocupam o topo do ranking. O Rio de Janeiro é o segundo estado com mais IES classificadas (20\%), apresentando também a maior diversidade, já que aparecem na classificação duas universidades federais (UFRJ e UFF), uma estadual (UERJ) e uma privada (PUCRio). O Quadro 4 apresenta as 20 primeiras posições na edição 2019 do RUF, com pontuação correspondente para cada um dos cinco indicadores, além da pontuação total. 
Quadro 4 - IES classificadas nas 20 primeiras posições do RUF edição 2019

\begin{tabular}{|c|c|c|c|c|c|c|}
\hline IES & Ensino & Pesquisa & Mercado & Inovação & Internacionalização & Pontuação total \\
\hline USP & 31,10 & 41,63 & 18,00 & 3,46 & 3,83 & 98,02 \\
\hline UNICAMP & 31,39 & 41,34 & 17,16 & 3,64 & 3,56 & 97,09 \\
\hline UFRJ & 31,10 & 40,54 & 17,72 & 3,86 & 3,78 & 97,00 \\
\hline UFMG & 31,47 & 40,27 & 17,91 & 3,53 & 3,54 & 96,72 \\
\hline UFRGS & 31,17 & 40,69 & 16,97 & 3,30 & 3,55 & 95,68 \\
\hline UNESP & 28,56 & 40,38 & 17,44 & 2,92 & 3,37 & 92,67 \\
\hline UFSC & 30,41 & 39,61 & 15,75 & 3,21 & 3,60 & 92,58 \\
\hline UFPR & 30,16 & 38,10 & 16,97 & 3,60 & 3,19 & 92,02 \\
\hline UnB & 30,60 & 38,19 & 15,94 & 2,98 & 3,50 & 91,21 \\
\hline UFPE & 29,01 & 36,73 & 17,44 & 3,33 & 3,26 & 89,77 \\
\hline UFC & 27,57 & 38,41 & 16,97 & 2,91 & 3,61 & 89,47 \\
\hline UFSCAR & 30,47 & 38,88 & 13,50 & 2,88 & 3,42 & 89,15 \\
\hline UERJ & 26,34 & 37,97 & 17,16 & 2,81 & 3,53 & 87,81 \\
\hline UFBA & 27,49 & 35,95 & 16,97 & 3,23 & 3,31 & 86,95 \\
\hline UFV & 29,74 & 37,94 & 12,84 & 3,54 & 2,78 & 86,84 \\
\hline UNIFESP & 29,88 & 40,64 & 9,84 & 2,91 & 3,46 & 86,73 \\
\hline UFF & 28,63 & 35,32 & 16,50 & 3,01 & 3,20 & 86,66 \\
\hline PUCRS & 24,59 & 36,35 & 16,5 & 3,40 & 3,47 & 84,31 \\
\hline PUCRio & 24,50 & 36,35 & 15,75 & 3,37 & 3,71 & 83,68 \\
\hline UFG & 26,83 & 34,54 & 16,50 & 2,95 & 2,76 & 83,58 \\
\hline
\end{tabular}

Fonte: Elaborado pelas autoras (2020).

A USP é a primeira colocada no Ranking Universitário Folha, com 98,02 pontos totais, seguida pela UNICAMP e UFRJ com 97,09 e 97,00 pontos, respectivamente. Observa-se que para as primeiras posições há uma diferença muito sutil nas pontuações, as IES alcançam quase $100 \%$ de pontuação em todos os indicadores, denotando alta qualidade das universidades brasileiras.

Observa-se que na sétima colocação no indicador Mercado, empatada com UNESP e Pontifícia Universidade Católica de São Paulo (PUCSP), encontra-se a UFPE, ressaltando a relevância da contratação de profissionais do nordeste do país, além das universidades do sudeste que tradicionalmente ocupam as primeiras posições. As 10 primeiras posições nesse indicador contemplam quatro universidades privadas, três estaduais e três federais. 
A nota do indicador Pesquisa é grandemente influenciada pela quantidade de docentes da instituição, pois é composta, em quase a sua totalidade, pela produção quantitativa da instituição. Assim, mostra-se uma surpresa a UNICAMP ocupar a segunda posição, à frente da UFRJ que possui o dobro de docentes (PRÓ-REITORIA DE PESQUISA UFRJ, 2020; UNICAMP, 2020).

Apesar de compor um ranking brasileiro, que privilegia alguns indicadores nacionais como Bolsistas CNPq e Publicações em revistas nacionais, observa-se que os resultados da edição 2019 do RUF não diferem dos resultados dos rankings internacionais league tables, onde USP, UNICAMP, UFRJ, UFMG e UFRGS se revezam nas primeiras posições (VANZ, 2018).

Vale ressaltar ainda que a classificação do RUF reconhece o empenho das próprias universidades, já que no topo do ranking estão algumas das instituições que se preocupam em melhorar seus resultados nessas avaliações, conforme apontam os PDIs da UFMG e UFC (ALVES; DRESSLER; VANZ, 2019).

Ao comparar resultados das IES brasileiras no RUF e no U-Multirank, observam-se duas diferenças: enquanto a UFMT aparece no U-Multirank, a Universidade Federal da Bahia (UFBA) se classifica no RUF na décima quarta posição. Observando o desempenho da USP no indicador Pesquisa, notam-se similaridades nos dois rankings, já que ambos consideram as publicações na Web of Science e apresentam um resultado semelhante. O mesmo acontece comparando os quesitos Inovação do RUF com Transferência de Conhecimento do UMultirank, em relação à mesma instituição.

No quesito Ensino, enquanto o RUF considera a titulação dos docentes, a dedicação integral e a nota dos alunos em uma avaliação nacional, o UMR observa a porcentagem de alunos que completam a graduação e o mestrado no tempo determinado.

\section{CONSIDERAÇÕES FINAIS}

A análise do U-Multirank e do Ranking Universitário Folha aponta algumas diferenças nos indicadores utilizados. O RUF trabalha com notas numéricas, enquanto o UMR estabelece conceitos além de notas. O RUF difere substancialmente em relação ao U-Multirank no que diz respeito aos critérios que levam em consideração a opinião de profissionais de recursos humanos sobre as suas preferências de contratação nos mercados de trabalho e especificidades.

Há uma diferença substancial de finalidade entre a avaliação multidimensional realizada pelo U-Multirank e a avaliação unidimensional realizada pelo RUF, visto que o primeiro deixa a critério do próprio usuário (estudantes, gestores de universidades, etc.) a interpretação de qual universidade considera a melhor de acordo com as suas necessidades. Por outro lado, o RUF disponibiliza uma lista com a classificação das melhores universidades brasileiras, estando no topo aquela considerada a melhor na soma dos indicadores. No entanto, tal classificação desconsidera as necessidades individuais de cada usuário e coloca as universidades como se todas fossem iguais, sem qualquer tipo de distinção, a não ser que o usuário escolha buscar as notas dos indicadores individualmente e assim optar pelo que considerar mais relevante.

A participação no U-Multirank é gratuita, solicitada pela instituição através do preenchimento de um formulário disponível no website. A visualização dos resultados através de conceitos e gráficos multidimensionais permite a identificação dos pontos fortes das instituições além de aspectos que podem ser aprimorados. As instituições brasileiras têm poucos indicadores conceituados o que decorre, possivelmente, do não preenchimento/envio dos 
questionários. Estes indicadores qualitativos, que poderiam ser a mola propulsora das IES nacionais, acabam ficando vazios.

Os rankings nacionais têm sua importância reconhecida no sentido de valorizar instituições generalistas, considerando-se que os rankings globais beneficiam universidades com enfoque nas ciências naturais e engenharias, em detrimento de instituições que trabalham com maior amplitude temática. As IES brasileiras são grandes e generalistas, o que dificulta sua visibilidade por parte dos rankings internacionais. O RUF dá visibilidade às instituições brasileiras que não aparecem nos rankings league tables, mas são consideradas instituições importantes no cenário nacional. Entre as primeiras colocadas, no entanto, não há nenhuma novidade. Da mesma forma, os indicadores utilizados pelos dois rankings apresentam resultados muito parecidos, mesmo que avaliem aspectos um tanto quanto diferentes.

Os rankings são ferramentas úteis, ainda que parciais, para diagnósticos e comparações em âmbito internacional, sobre o desempenho das instituições, ajudando no desenvolvimento de medidas institucionais e políticas de governo para aprimoramento das universidades. Os rankings permitem uma discussão sobre o papel das universidades além da sua inserção nacional ou regional, em seus vários aspectos, o que, sem dúvida, contribui para o aperfeiçoamento das instituições e, em última análise, do sistema de educação do país. De forma geral, os rankings apontam quais aspectos carecem de mais desenvolvimento em uma instituição e quais oferecem destaque, porém, também servem como motivadores de mudanças e melhorias visando uma melhor classificação no próprio ranking para assim melhorar a reputação da instituição.

Em razão da relevância desta contribuição, recomendam-se estudos futuros acerca do tema, com novas análises a fim de verificar se as IES brasileiras estão obtendo melhores conceitos no U-Multirank, bem como a atribuição no que se refere aos indicadores baseados em questionários. Além disso, recomenda-se o acompanhamento do ingresso de instituições que se cadastram neste ranking internacional. Estudos futuros sobre o RUF são de igual importância, pois este é um ranking nacional e que abrange as IES de acordo com a realidade do país, diferentemente dos rankings globais. Com isso, novos estudos sobre seus indicadores e metodologias são de vital importância para melhorar o desempenho do ensino superior em nível nacional e, consequentemente, mundial.

\section{FINANCIAMENTO}

Esta pesquisa é financiada pelo Conselho Nacional de Desenvolvimento Científico e Tecnológico (CNPq), processo 304736/2019-8; pela Pró-reitoria de Pesquisa da Universidade Federal do Rio Grande do Sul, Programa de Iniciação Científica; e pela Fundação de Amparo à Pesquisa do Rio Grande do Sul (FAPERGS) Processo 19/2551-0001968-8.

\section{REFERÊNCIAS}

ALVES, A. B. V.; DRESSLER, C. G.; VANZ, S. A. S. Rankings acadêmicos nas universidades públicas brasileiras: presença no planejamento estratégico e nas notícias institucionais. In: Rankings acadêmicos e governança universitária no espaço do ensino superior de língua portuguesa: Angola, Cabo Verde, Macau, Moçambique, Portugal e Brasil. Brasília, DF: Anpae, 2019. p. 164-181. 
AXEL-BERG, J. Indicadores para efeito de comparação internacional no ensino superior brasileiro. In: MARCOVITCH, J. (Org.). Repensar a universidade: desempenho acadêmico e comparações internacionais. São Paulo: Com-Arte; Fapesp, 2018. p. 31-44.

BRASIL. Presidência da República. Lei no 10.861, de 14 de abril de 2004. Institui o Sistema Nacional de Avaliação da Educação Superior - SINAES e dá outras providências. Brasília, 2004. Disponível em: http://www.planalto.gov.br/ccivil 03/ ato2004-

2006/2004/lei/l10.861.htm. Acesso em: 2 mar. 2020.

CALDERÓN, A. I.; LOURENÇO, H. S. Rankings na educação superior brasileira: uma aproximação aos rankings públicos e privados. Revista de Estudos Aplicados em Educação, São Caetano do Sul, v. 2, n. 3, p. 89-103, 2017.

CALDERÓN, A. I.; MATIAS, R. C.; LOURENÇO, H. S. Rankings na educação superior: as melhores faculdades do brasil (1982-2000). Estudos em Avaliação Educacional, São Paulo, v. 25, n. 57, p. 226-247, 2014.

CALDERÓN, A. I.; PFISTER, M.; FRANÇA, C. M. Rankings acadêmicos na educação superior brasileira: a emergência de um campo de estudo (1995-2013). Roteiro, Joaçaba, v. 40, n. 1, p. 31-50, 2015.

COORDENAÇÃO DE APERFEIÇOAMENTO DE PESSOAL DE NÍVEL SUPERIOR. Plano Nacional de Pós-graduação (PNPG) 2011-2020. Brasília, DF: CAPES, 2010a.

COORDENAÇÃO DE APERFEIÇOAMENTO DE PESSOAL DE NÍVEL SUPERIOR. Plano Nacional de Pós-graduação (PNPG) 2011-2020. Brasília, DF: CAPES, 2010 b.

COORDENAÇÃO DE APERFEIÇOAMENTO DE PESSOAL DE NÍVEL SUPERIOR. Avaliação multidimensional de programas de pós-graduação. Brasília, DF: CAPES, 2019.

DIAS SOBRINHO, J. Avaliação ética e política em função da educação como direito público ou como mercadoria? Educação \& Sociedade, Campinas, v. 25, n. 88, p. 703-725, 2004.

FEDERKEIL, G. et al. An interactive multidimensional ranking web tool. In: VAN VUGHT, F. A.; ZIEGELE, F. (Org.). Multidimensional ranking: the design and development of U-Multirank. Germany: Springer, 2012. p. 167-177. Disponível em: https://doi.org/10.1007/978-94-0073005-2. Acesso em: 26 fev. 2020.

GOGLIO, V. One size fits all? a different perspective on university rankings. Journal of Higher Education Policy and Management, England, v. 38, n. 2, p. 212-226, 2016.

HAZELKORN, E. Como os rankings estão remodelando o ensino superior. In: Rankings acadêmicos e governança universitária no espaço do ensino superior de língua portuguesa: Angola, Cabo Verde, Macau, Moçambique, Portugal e Brasil. Brasília, DF: Anpae, 2019. p. 2232. 
HAZELKORN, E.; LOUKKOLA, T.; ZHANG, T. Rankings in institutional strategies and processes: impact or illusion? Brussels: European University Association, 2014.

MARCOVITCH, J. (Org.). Repensar a universidade: desempenho acadêmico e comparações internacionais. São Paulo: Com-Arte; Fapesp, 2018.

PRÓ-REITORIA DE PESQUISA UFRJ. A UFRJ. Rio de Janeiro, 2020. Disponível em: https://pessoal.ufri.br/index.php/a-ufri. Acesso em: 2 mar. 2020.

RANIERI, N. Universidades e rankings globais: tensões jurídicas. In: MARCOVITCH, J. (Org.). Repensar a universidade: desempenho acadêmico e comparações internacionais. São Paulo: Com-Arte; Fapesp, 2018. p. 147-163.

RIGHETTI, Sabine. Qual é a melhor?: origem, indicadores, limitações e impactos dos rankings universitários. 2016. Tese (Doutorado em política científica e tecnológica) - Instituto de Geociências, Universidade Estadual de Campinas, Campinas, SP, 2016. Disponível em: http://repositorio.unicamp.br/handle/REPOSIP/321911. Acesso em: 8 ago. 2019.

RIGHETTI, S. Avaliar para comparar: os rankings britânico e chinês no ensino superior global. In: MARCOVITCH, J. (Org.). Repensar a universidade: desempenho acadêmico e comparações internacionais. São Paulo: Com-Arte; Fapesp, 2018. p. 45-62.

RIGHETTI, S. Dúvidas sobre o RUF. Destinatário: Samile Andrea de Souza Vanz. Porto Alegre, 20 fev. 2020. E-mail.

STREHL, L. et al. Brazilian science between national and foreign journals: methodology for analyzing the production and impact in emerging scientific communities. PLuS One, San Francisco, v. 11, n. 5, p. 1-15, 2016.

U-MULTIRANK. University and College Rankings. Germany, 2019a. Disponível em: https://www.umultirank.org/. Acesso em: 4 jun. 2019.

U-MULTIRANK. Frequently asked questions (FAQ). Germany, 2019b. Disponível em: https://www.umultirank.org/press-media/documents/FAQ U-Multirank 2019.pdf. Acesso em: 4 jun. 2019.

U-MULTIRANK. U-Multirank project. Germany, 2019c. Disponível em:

https://www.umultirank.org/about/u-multirank/. Acesso em: 4 jun. 2019.

U-MULTIRANK. Data Request. Destinatário: Samile Andrea de Souza Vanz. Germany, 6 nov. 2019d. E-mail.

UNICAMP. Professores. Campinas, 2020. Disponível em: https://www.unicamp.br/unicamp/professores. Acesso em: 2 mar. 2020.

VANZ, S. A. S. O que medem os rankings universitários internacionais? Apontamentos teóricos, indicadores e características. Informação \& Sociedade: estudos, João Pessoa, v. 28, n. 2, 
p. 83-92, maio/ago. 2018. Disponível em:

https://periodicos.ufpb.br/ojs/index.php/ies/article/view/38383/20794. Acesso em: 2 jun. 2019.

VANZ, S. A. S. et al. Rankings universitários internacionais e o desafio para as universidades brasileiras. Encontros Bibli: revista eletrônica de biblioteconomia e ciência da informação, Florianópolis, v. 23, n. 53, p. 39-51, 2018a. Disponível em: https://periodicos.ufsc.br/index.php/eb/article/view/1518-2924.2018v23n53p39/37375. Acesso em: 2 jun. 2019.

VANZ, S. A. S. et al. O desempenho das universidades brasileiras no Leiden Ranking. In: BENETTI, M.; BALDISSERA, R. (org.). Pesquisa e Perspectivas de Comunicação e Informação. Porto Alegre: Sulina, 2018b. p. 276-290.

WESTERHEIJDEN, D. F. U-Multirank: the implementation of a multidimensional international ranking: where are we, where are we going?. 2014. Disponível em: http://www.acasecretariat.be/fileadmin/aca_docs/images/members/Don_Westerheijden.pdf. Acesso em: 2 jun. 2019. 